\title{
Laser Device
}

National Cancer Institute

\section{Source}

National Cancer Institute. Laser Device. NCI Thesaurus. Code C50026.

A device designed to emit a monochromatic beam of coherent light. 